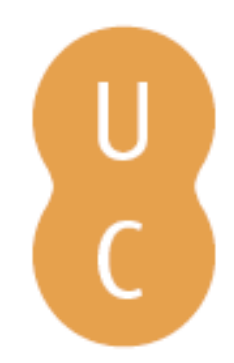

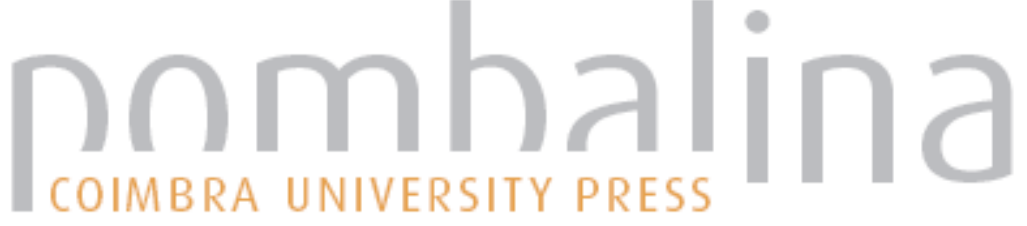

\section{Delimitação, natureza e funções do discurso mediático}
Autor(es):
Rodrigues, Adriano Duarte
Publicado por: Imprensa da Universidade de Coimbra
URL persistente:
URI:http://hdl.handle.net/10316.2/36641
DOI:
DOI:http://dx.doi.org/10.14195/978-989-26-0873-0_2

Accessed : $\quad$ 26-Apr-2023 05:48:17

A navegação consulta e descarregamento dos títulos inseridos nas Bibliotecas Digitais UC Digitalis, UC Pombalina e UC Impactum, pressupõem a aceitação plena e sem reservas dos Termos e Condições de Uso destas Bibliotecas Digitais, disponíveis em https://digitalis.uc.pt/pt-pt/termos.

Conforme exposto nos referidos Termos e Condições de Uso, o descarregamento de títulos de acesso restrito requer uma licença válida de autorização devendo o utilizador aceder ao(s) documento(s) a partir de um endereço de IP da instituição detentora da supramencionada licença.

Ao utilizador é apenas permitido o descarregamento para uso pessoal, pelo que o emprego do(s) título(s) descarregado(s) para outro fim, designadamente comercial, carece de autorização do respetivo autor ou editor da obra.

Na medida em que todas as obras da UC Digitalis se encontram protegidas pelo Código do Direito de Autor e Direitos Conexos e demais legislação aplicável, toda a cópia, parcial ou total, deste documento, nos casos em que é legalmente admitida, deverá conter ou fazer-se acompanhar por este aviso.

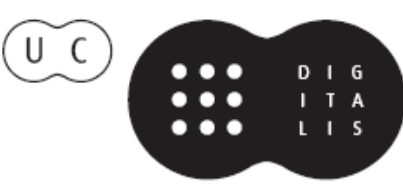


www.uc.pt/ imprensa_uc CONTACTO imprensa@uc.pt VENDAS ONLINE http://livrariadaimprensa.uc.pt JANEIRO 2015


\section{DE JORNALISMO CONTRA A INDIFERENÇA}

TEXTOS DE

Marc Lits, Adriano Duarte Rodrigues, Tito Cardoso e Cunha, José Augusto Mourão, Alberto Pena Rodríguez, Maria Augusta Babo, Daniel Cronu, João Pissarra Esteves, Gilles Gauthier, Heloísa Paulo e Luís Reis Torgal, Alfredo Barroso, António Fidalgo, Nöel Nel, João de Almeida Santos, Juan Luis Cebrián, António Dias Figueiredo, Marina Themudo, Jorge Sampaio, Nelson Traquina, Mário Soares
( livro que agora se apresenta, nasce de dois desígnios fundamentais: por um lado, celebrar duas décadas de ensino do Jornalismo na Universidade de Coimbra e, por outro, partilhar com um público mais alargado um conjunto de reflexões sobre os media, o jornalismo, a comunicação e o espaço público.

Se o ensino superior do Jornalismo em Portugal, relativamente tardio em relação ao resto da Europa, deu os seus primeiros passos no fim dos anos 70 do século passado, ele aparece apenas duas décadas depois na academia coimbrã. Contudo, esta foi, no contexto nacional, a primeira licenciatura em Jornalismo, distinguindo-se, quer em título, quer em objetivos, das licenciaturas então existentes no país. A criação de uma Licenciatura em Jornalismo na Universidade de Coimbra, em 1993-1994, foi, por si, um acontecimento. Com efeito foi necessário que reitor, professores e jornalistas ousassem atualizar a oferta curricular da Faculdade de Letras, oferecendo um curso há muito desejado pela sociedade e pelo mercado, embora desconsiderado por alguns setores da academia. Correndo o risco de omitir alguém, a quem antecipadamente pedimos desculpa, não podemos deixar de recordar os esforços dos jornalistas João Mesquita, João Fonseca, em representação
Todas as gerações, sem dúvida, se julgan para refazer o mundo. A minha sabe, nc que não poderá refazê-lo. A sua tarefa é tc

Consiste em impedir que se desfaça, $p$ unicamente das suas negações A. Camus, Discursos da Suécia (1957)

do Sindicato dos Jornalistas, e de Jorge Castilho, a quem mais tarde se viria associar o nome de Mário Martins, bem como o do então Reitor da Universidade de Coimbra Rui Alarcão, e dos professores João Roque e Luís Reis Torgal. Entre 1993 e 1996, a Licenciatura em Jornalismo funcionou com um Secretariado, que teve um papel executivo e científico nos primeiros tempos do curso na FLUC. Presidido pelo Presidente do Conselho Científico Ludwig Scheidl, este 


\title{
Delimitação, Natureza e Funções do Discurso Mediático
}

\author{
Adriano Duarte Rodrigues
}

Universidade Nova de Lisboa-FCSH

\section{Introdução}

O discurso não é uma das instituições mediáticas; é o seu principal produto e o resultado final do seu funcionamento. Os media produzem discursos como os pintores pintam telas, os músicos compõem músicas, os arquitetos projetam edifícios. É claro que os media desempenham também outras funções, mas todas elas têm no discurso o seu objetivo e a sua expressão final.

Uma das principais características do discurso mediático é o facto de se apresentar como um discurso acabado e de funcionar aparentemente sem intermitências nem vazios. O funcionamento dos discursos espontâneos, dos discursos que trocamos uns com os outros no decurso da vida quotidiana, é intermitente, pontuado por todo um conjunto de hesitações, de esperas, de ruturas, de silêncios, de derivas. O discurso mediático, pelo contrário, flui de maneira constante e ininterrupta, encadeia enunciados que se apresentam habitualmente de forma acabada, escondendo os seus processos de gestação.

Este efeito de completude resulta da camuflagem do processo de enunciação, através do uso predominante da terceira pessoa que, como sabemos, é forma verbal da não-pessoa. $\mathrm{O}$ uso predominante da terceira pessoa garante ao discurso mediático, como aliás também aos discursos históricos e científicos, uma estratégia de universalidade referencial dos enunciados, uma credibilidade da narração dos factos independente do lugar de fala do enunciador.

No discurso mediático, os silêncios são intoleráveis, uma vez que assinalam a perda da relação com o público e são, por conseguinte, encarados como um risco letal para o próprio funcionamento do seu dispositivo de enunciação. Falar, falar sempre, mesmo que seja para não dizer nada; falar apenas para manter a antena aberta, para não perder o contacto com o público, para preencher a programação, para encher a página do jornal. É por isso que uma das funções comunicacionais mais importantes do discurso mediático, além da função referencial, que consiste em dar conta dos acontecimentos que ocorrem no mundo, é a função fática, que consiste na manutenção do contacto com o público. 
E, no entanto, existem diversas modalidades de silêncio no funcionamento do discurso dos media. E, antes de mais, a do silêncio dos destinatários, a ausência de palavra por parte do público. É este silêncio que torna o público presente, instituindo-o como uma autêntica instância de interlocução.

Ao contrário do que as teorias clássicas da comunicação pressupõem, o silêncio do público não é simples ausência passiva de palavra; é um processo ativo e específico de elaboração do sentido, o processo de escuta. Apesar de silencioso, o público está presente na cadeia de elaboração do discurso, e é deste silencioso processo de escuta que o discurso dos media recebe o seu princípio, o seu alimento, a sua razão de ser, o seu sentido.

É indispensável fazer a distinção entre ouvir ou escutar um discurso e ser o seu destinatário. Posso ouvir eventualmente aquilo que duas pessoas dizem uma à outra, através das paredes de minha casa, ao passar por elas na rua ou ao viajar ao lado delas num transporte público, sem que aquilo que dizem uma à outra me seja dirigido ou tenha a ver comigo. Ser destinatário de um discurso é ser envolvido por ele, ser alvo do seu sentido, ser obrigado a responder às suas interpelações, deixar-se ir na direção que ele próprio produz, orienta e dirige. Deste modo, o público do discurso mediático não é constituído por aqueles que o ouvem ou escutam, mas por aqueles que, de algum modo, são os seus destinatários, são por ele interpelados ou envolvidos. É esta escuta específica daqueles que se sentem envolvidos pelo discurso mediático que constitui o público.

Uma precisão de natureza metodológica. Não é minha intenção proceder a uma crítica negativa do discurso mediático, emitir juízos acerca das suas virtudes ou dos seus vícios eventuais, a partir de conceções morais mais ou menos implícitas. Também não pretendo fornecer normas ou preceitos, dar conselhos acerca da melhor maneira de produzir "bons" discursos mediáticos. Se tivesse esses objetivos, teria de partir de pressupostos moralizantes que estão fora das minhas pretensões. Apenas pretendo, muito mais modestamente, contribuir para uma crítica positiva, procedendo a uma delimitação do seu âmbito, a uma identificação da sua natureza e dos seus modos de funcionamento, a uma averiguação das suas relações com as outras modalidades de discurso e das funções que ele desempenha no seio das sociedades modernas.

\section{O problema da delimitação das fronteiras do discurso mediático}

Se a delimitação das fronteiras de qualquer discurso é uma tarefa complexa, em virtude da sua relativa fluidez e heterogeneidade, da sua natureza multifacetada e polimórfica, a delimitação do discurso mediático é uma tarefa 
ainda mais difícil devido à sua capacidade de circulação por todo o tipo de discursos e de infiltração nas restantes práticas discursivas.

É precisamente esta aptidão para contaminar as outras modalidades de discurso e para se deixar por elas contaminar que confere ao discurso mediático as características que o habilitam a exercer as suas funções de mediação.

Será que podemos tomar como critério para a delimitação das fronteiras do discurso mediático o seu suporte de difusão, definindo-o como discurso difundido pelos dispositivos mediáticos da informação? Poderemos considerar toda a prática da linguagem que é produzida pelas instituições da informação como discurso mediático? Não haverá também discursos mediáticos fora dos aspectos da informação e os suportes informativos não difundirão também discursos não mediáticos?

Este critério do suporte de difusão não é aceitável, uma vez que uma das características da prática discursiva dos media é precisamente a de ser um domínio da experiência extremamente poroso e permeável, sem fronteiras estanques. O facto de as relações entre o discurso mediático e as outras modalidades de discurso serem marcadas por todo o tipo de contaminação recíproca faz com que encontremos discursos mediáticos que não são veiculados pelos órgãos de informação assim como também encontremos nos órgãos de informação discursos não mediáticos.

\section{A natureza exotérica do discurso mediático}

A característica distintiva do discurso mediático é o facto de o âmbito da sua legitimidade não ser delimitado pelas fronteiras de um domínio restrito da experiência. Enquanto o âmbito da legitimidade dos outros tipos de discurso é limitado a um dos domínios específicos da experiência, o âmbito da legitimidade do discurso mediático é transversal ao conjunto de todos os domínios da experiência moderna. Para dar conta desta distinção dizemos que os discursos não mediáticos são esotéricos, ao passo que o discurso mediático é exotérico ${ }^{1}$.

O imperativo de transparência ou de visibilidade universal do discurso mediático tem a ver diretamente com esta natureza exotérica da sua simbó-

\footnotetext{
${ }^{1}$ Esotérico é aqui um termo técnico para designar o discurso destinado aos membros de uma instituição, exigindo a sua compreensão o domínio das suas representações simbólicas próprias, o que o torna relativamente opaco para os estranhos, aos que não pertencem ao corpo legítimo dessa instituição. Exotérico, pelo contrário, aplica-se às modalidades discursivas que não são reservadas a um corpo institucional em particular, mas destinadas a todos indiscriminadamente.
} 
lica, enquanto a relativa opacidade das outras modalidades de discurso tem a ver com a natureza esotérica da sua simbólica. Assim, por exemplo, o discurso médico tende a cair e impor, não só um vocabulário e regras sintáticas próprias, mas também formas simbólicas esotéricas da sua expressão e da sua difusão. É por isso que o discurso médico é relativamente incompreensível e opaco para os que não são detentores da legitimidade de intervenção expressiva e pragmática no seu domínio específico de experiência, para aqueles que não fazem parte do seu corpo legítimo. O proverbial hermetismo da escrita de médicos assegura esta função esotérica do funcionamento da instituição da medicina. A experiência da medicina também tem obviamente acesso ao discurso mediático, uma vez que este também se apropria de uma parte da simbólica médica, enquanto prática discursiva transversal às outras modalidades de discurso. Mas, ao apropriar-se dela, o discurso mediático tende a torná-la transparente e universalmente compreensível, em função da natureza exotérica do seu funcionamento.

É por isso que, ao contrário da natureza sacralizada do lugar de fala autorizado das outras instituições, a cena sobre o fundo da qual se recortam os lugares de fala dos enunciadores autorizados do discurso mediático é um lugar simbólico dessacralizado. ${ }^{2}$

Esta distinção entre a opacidade dos discursos das outras instituições e a transparência do discurso mediático é particularmente importante. Uma das suas consequências mais evidentes é o facto de o funcionamento do discurso mediático levar com frequência os detentores da legitimidade das outras instituições a considerarem que o discurso mediático atraiçoa a autenticidade do seu discurso especializado.

Mas há uma outra consequência do funcionamento exotérico do discurso mediático, a do seu contributo positivo para a permeabilidade dos discursos das outras instituições e para a homogeneidade das sociedades modernas.

\section{A natureza metafórica do discurso mediático}

A contaminação provocada pelo discurso mediático entre as diferentes modalidades discursivas é responsável pela natureza metaforizante da prática discursiva mediática. Este facto de assimilar parte da dimensão discursiva

\footnotetext{
${ }^{2}$ Sacralizado contrapõe-se aqui a secularizado, como o reservado, o colocado à parte, se contrapõe a não reservado, ao que está aberto a todos e é portanto do domínio público. O termo sacralizado corresponde à dimensão simbólica da modalidade esotérica de discurso, enquanto o termo secularizado tem a ver com a dimensão simbólica da modalidade exotérica de discurso.
} 
das outras instituições contribui para a função de mediação de que o discurso mediático é responsável .

A título de exemplo, observemos alguns títulos retirados da revista brasileira Veja, nos quais podemos apreciar metáforas forjadas por transposição do discurso religioso, do discurso militar e do discurso desportivo:

Transposições do discurso religioso:

"Templos da leitura"

"Anjo na cabine. Menina de 7 anos morre pilotando avião"

"Pecados da cama. Doença da vaca louca arrasa pecuária britânica e a ciência tem poucas respostas sobre o mal"

"O prazer da carne. Feito em casa ou nos rodízios que se multiplicam, o churrasco se torna o mais popular prato típico brasileiro"

Transposições do discurso militar:

"A revolução dos velhos. Os brasileiros com mais de 60 anos formam uma geração dourada. Têm renda e património maiores do que os mais jovens. Eles nasceram, cresceram e envelheceram quando o país prosperava"

"Operação Relâmpago. Banco Central intervém no Banorte num ataque de surpresa, e transfere seu controle para o Bandeirantes"

"A guerra ao câncer"

"O Nordeste invade o Japão. O bate-boca entre o cearense Tasso e o maranhense Sarney em torno da CPI ofusca a viagem a Tóquio"

"Guerra de cinderelas"

"A guerra pela rede. Criada por um estudante recém-formado, a Netscape desafia o poder da Microsoft com novos programas de acesso na Internet"

Transposições do discurso desportivo:

"Na Marca do Pênalti. Acusado de assédio sexual por duas mulheres, Wanderley Luxemburgo tem de jogar na defesa".

"A baixinha mostra o jogo"

"A roda global"

"Republicanos patinam na largada"

"Xadrez sangrento. Com mais dinheiro que os governos estaduais e federal, as prefeituras se tornam peças decisivas no jogo político".

Além da dimensão discursiva, as instituições possuem ainda uma dimensão pragmática, visto serem detentoras da competência para intervir com efi- 
cácia no domínio da experiência de que detêm a legitimidade. Apesar de a dimensão discursiva das instituições se contrapor à sua dimensão pragmática, como o dizer se contrapõe ao fazer, há uma relação quiasmática entre essas vertentes, na medida em que a palavra também possui a sua eficacidade e a ação também é dotada de expressividade simbólica. No entanto, a dimensão pragmática, isto é, a competência que as instituições possuem para intervir com eficácia num domínio da experiência, escapa ao domínio do discurso mediático.

Não é da totalidade da dimensão expressiva das outras instituições que o discurso mediático se apropria. Cada uma das instituições mantém normalmente intacta e ao abrigo da interferência da instituição mediática uma parte da sua dimensão expressiva, a componente a que demos o nome de esotérica, a que é reservada aos seus membros, aos legítimos detentores do seu poder simbólico. É apenas da componente destinada a um público indiferenciado, da componente a que demos o nome de exotérica, que o discurso mediático se apropria. O facto de o discurso mediático se apropriar exclusivamente da componente exotérica do discurso das outras instituições tem como consequência uma reelaboração dessacralizante dos diferentes discursos institucionais.

Para esta reelaboração do discurso das outras instituições de modo a adequá-lo às exigências do discurso mediático, as instituições dotam-se habitualmente de um corpo especializado de profissionais da mediatização, constituído nomeadamente por adidos de imprensa, porta-vozes, agentes da informação e de relações públicas.

As fronteiras entre as componentes esotérica e exotérica da dimensão expressiva não são, no entanto, sempre claras nem indiscutíveis, mas marcadas por relações de permanente tensão, que podem muitas vezes espoletar situações de conflito. As recentes discussões em torno das competências do discurso mediático para dar conta com legitimidade dos discursos político e jurídico, perspetivadas dos pontos de vista deontológico e ético, são bons exemplos da natureza tensional destas relações.

Em geral, a dimensão discursiva assegura quatro funções institucionais: as funções pedagógica, tradicional, simbólica, mobilizadora e reparadora. É pelo discurso que as instituições asseguram a inculcações e a transmissão da sua legitimidade para ditar as normas destinadas a regular os comportamentos e para intervir com eficácia dentro de um determinado domínio da experiência. Mas é também ao discurso que compete expressar simbolicamente a visibilidade da sua intervenção, a mobilização em torno da sua ordem de valores e a reparação da violação das suas normas. 


\section{A função especular do discurso mediático}

Sendo a modernidade marcada pela autonomia das esferas da experiência, as sociedades modernas correriam o risco de dissolução, de prosseguirem um conjunto de objetivos desgarrados, heteróclitos e sem sentido, se não pudessem contar com procedimentos destinados a assegurar a composição entre os interesses heterogéneos das diferentes instituições. É a instituição mediática que desempenha, nas sociedades modernas, este papel estratégico de composição e de consequente cimento homogeneizador da vida coletiva. Nela vem refletir-se, como num espelho, a diversidade das funções pedagógicas, simbólicas, mobilizadoras e reparadoras das restantes instituições. Esta função especular que a instituição mediática desempenha em relação às outras instituições é, por conseguinte, indispensável para a homogeneidade das sociedades modernas. O seu contributo não só torna visível a ordem axiológica e a legitimidade de cada uma das outras instituições, mas também assegura o indispensável confronto entre a diversidade das suas pretensões legítimas.

\section{As funções estratégicas de composição do discurso mediático}

Em relação às pretensões legítimas das instituições tradicionais, o discurso mediático desempenha um papel estratégico de composição entre os seus diferentes interesses. Podemos distinguir diversas modalidades estratégicas de composição entre os interesses das diferentes instituições. As mais importantes são as modalidades de naturalização, de reforço, de compatibilização, de exacerbação dos diferendos, de transparência e de alteração do regime de funcionamento.

\section{As estratégias de naturalização}

Uma das principais funções estratégicas do discurso mediático é a de naturalizar o recorte arbitrário da multiplicidade de domínios da experiência realizado na modernidade assim como o poder legítimo, tanto expressivo como pragmático, que as instituições detêm sobre eles. A apropriação por parte do discurso mediático de parte da dimensão expressiva das outras instituições tende a naturalizar as pretensões legítimas construídas historicamente pelos corpos autorizados dessas instituições, a apresentá-las como naturalmente fundadas e, por conseguinte, indiscutíveis, o que tem como efeito mais importante a modernização dos fundamentos da legitimidade das outras instituições. 
Esta função estratégica pressupõe uma determinada relação com a memória ou, melhor dizendo, com a dimensão mnésica do discurso mediático. O entrelaçamento do esquecimento, resultante da efemeridade dos seus enunciados, com o seu retorno regular, sob a forma de retrospectivas e de citações, é um dos mecanismos fundamentais desta dimensão mnésica do discurso mediático.

Se o discurso mediático prossegue, por um lado, um notável efeito de esquecimento e de arquivação, por outro, alimenta-se do incessante mecanismo de rememoração das formas que vai arquivando. Esta forma ritualizada da alternância dos mecanismos de esquecimento e de rememoração é um dos processos mais importantes de produção dos efeitos de habituação e de naturalização.

\section{As estratégias de reforço}

Mas o discurso mediático desempenha também um importante papel estratégico de reforço da legitimidade das outras instituições, garantindo a sua permeabilidade por todo o tecido social. Este papel de reforço resulta da projeção pública da sua simbólica, como efeito da visibilidade que lhes confere, ajudando a mantê-las presentes no imaginário social.

\section{As estratégias de compatibilização}

Nos casos em que, no entanto, a legitimidade das diferentes instituições se revela contraditória ou estas entram em competição na luta pela imposição da sua legitimidade para impor os seus valores e as suas normas num determinado domínio da experiência, o discurso mediático desempenha um papel particularmente importante de compatibilização entre essas pretensões legítimas contraditórias.

Os processos mais importantes que asseguram este papel de compatibilização consiste na elaboração de uma retórica destinada a esvaziar os discursos em confronto das formulações mais polémicas, substituindo-as por enunciados formais com os quais os detentores legítimos das diferentes posições em confronto não podem deixar de concordar.

É este processo de esvaziamento da conflitualidade nas sociedades modernas que confere ao discurso mediático a natureza exotérica que o torna apto para assegurar as suas funções de mediação.

Nos casos mais difíceis, em que não existem disponíveis processos retóricos de compatibilização entre as pretensões legítimas concorrentes, a apresentação das diferentes posições em presença, nomeadamente sob a forma 
de mesas redondas, de debates entre os representantes legítimos dessas pretensões ou de textos editoriais na imprensa desempenham semelhante papel de compatibilização, mantendo a instituição mediática ao abrigo da contestação sistemática de que são alvos as posições contraditórias em presença.

Uma das manifestações atualmente mais frequentes desta estratégia é a dos debates acerca das instituições religiosas, políticas e médica e regular, cada uma por si, o discurso e os comportamentos no domínio do aborto. Tratando-se de um domínio associado à própria experiência da vida, o que, no imaginário, releva da fundação arqueológica de cada uma das instituições em confronto, a apresentação do somatório das instituições em confronto, a apresentação do somatório das suas posições por parte da instituição permite garantir à instituição mediática a sua autonomia institucional de promotora dos valores da visibilidade e às instituições concorrentes o reforço das suas posições relativas.

\section{As estratégias de exacerbação dos diferendos}

Mas nem sempre o discurso mediático desempenha um papel harmonizador ou de compatibilização entre as pretensões legítimas divergentes. Por vezes, tende a exacerbar essas diferenças, espoletando ou agravando os diferendos. Muitos dos atuais conflitos são empolados e por vezes espoletados, na sequência da sua encenação mediática.

\section{As estratégias de visibilidade}

O discurso mediático é a instituição por excelência destinada a dar visibilidade pública às outras instituições. Esta função está intimamente associada à natureza exotérica da sua simbólica. O facto de termos hoje à nossa disposição a instituição mediática faz com que aquilo que não seja objeto da sua intervenção mediadora não tenha existência socialmente reconhecida.

\section{A alteração dos regimes de funcionamento}

O discurso mediático assegura ainda alterações significativas no regime de funcionamento das instituições, quer acelerando quer desacelerando o ritmo e a intensidade do seu funcionamento. Assim, por exemplo, assistimos, no domínio do económico, ora a efeitos de aquecimento e de inflação ora a efeitos de arrefecimento ou de deflação, como resultado da projeção mediática das decisões tomadas pelos agentes com competência de intervenção na esfera dos valores económicos. No domínio do político, o discurso mediático 
ora normaliza e arrefece ora revoluciona e aquece a luta pela detenção do exercício do poder.

Podemos verificar idêntica função na instituição militar, detentora da legitimidade no domínio dos valores da defesa coletiva, na instituição religiosa, detentora da legitimidade no domínio dos valores da salvação, na instituição médica, detentora da legitimidade no domínio dos valores da saúde, na instituição escolar, detentora da legitimidade no domínio dos valores do saber. Cada uma destas instituições vê assim os seus ritmos, a sua intensidade e a velocidade de funcionamento acelerados ou travados em função da mediatização e da consequente projeção pública dos seus discursos e das suas intervenções próprias.

A análise das diferentes funções estratégicas que o discurso mediático desempenha permite portanto compreender, não só as suas fronteiras, mas sobretudo a sua permeabilidade pelos outros discursos. Poderíamos dizer que a linha de demarcação do discurso mediático passa pela natureza especular, pelo facto de nele virem refletir-se constantemente os discursos das outras instituições.

A identificação da natureza e o inventário das suas características ajudarnos-á agora a melhor delimitar com algum rigor o domínio do discurso mediático e distingui-lo das outras modalidades de discurso.

\section{A relação enunciativa do discurso mediático}

A característica discursiva que distingue o discurso mediático das outras modalidades de discurso é a natureza específica da sua relação enunciativa.

Nos discursos face a face, nos discursos que se desenrolam em presença entre dois ou mais interlocutores no decurso da vida quotidiana, locutor e alocutário tornam-se destinadores e destinatários de enunciados, de acordo com uma alternância regular da tomada da palavra. O discurso mediático, pelo contrário, é unilateral. Um enunciador dirige a palavra a um público relativamente indiferenciado e ausente, que não tem possibilidade de tomar efetivamente a palavra, pelo menos no decurso da relação mediática.

Há obviamente também outras modalidades de discurso em que a relação interlocutiva é caraterizada pela unilateralidade da enunciação. É o caso, antes de mais, dos discursos produzidos pelas instituições religiosa, militar, médica, em que um sujeito da enunciação, suposto saber, detém o monopólio da palavra e o dirige a sujeitos, supostos não saber. Os destinatários dos discursos destas instituições não constituem, no entanto, ao contrário dos destinatários do discurso mediático, um público indiferenciado, mas 
são constituídos precisamente como destinatários do discurso pelo facto de serem definidos por uma identidade relativamente fixa, pelo facto de serem respetivamente fiéis, guerreiros, súbditos e pacientes. Também no discurso literário um autor se dirige a um público indiferenciado e ausente, a um público que não tem a possibilidade de tomar a palavra. Mas, nesse caso, o leitor faz uma opção positiva, escolhe a obra e tem com o discurso literário uma relação personalizada. No discurso mediático, o público não escolhe a natureza interlocutiva de que é destinatário.

É claro que, num esforço para aproximar os processos da enunciação mediática dos processos da enunciação do discurso face a face, a instituição mediática utiliza habitualmente todo um conjunto de procedimentos que são definidos, de maneira esclarecedora, pelo facto de visarem "dar a palavra ao público". É o caso dos telefonemas em direto na rádio e na televisão ou das cartas ao Diretor e da correspondência dos leitores dos jornais e das revistas. Estes procedimentos não anulam, no entanto, fundamentalmente a unilateralidade da relação enunciativa do discurso mediático. Em primeiro lugar, porque não são propriamente processos de tomada da palavra por parte do espectador, do ouvinte ou do leitor, mas estratégias de condescendência por parte do locutor e são, como tais, subordinadas a uma seleção realizada pela própria instituição mediática. Em segundo lugar, porque não se trata de procedimentos de interlocução, mas de simulacros da interlocução, procedimentos artificiais mais ou menos sofisticados.

A natureza unilateral da relação enunciativa é, por conseguinte, um bom critério para distinguir, nos suportes mediáticos da informação, as modalidades mediáticas de discurso de outras modalidades de discurso. Tanto a televisão ou a rádio como a imprensa escrita servem por vezes de suporte a discursos não mediáticos. Os anúncios e as mensagens pessoais publicadas na imprensa escrita ou dirigidas através da rádio a correspondentes individuais, a televisão à la carte e as teleconferências dificilmente podem ser consideradas como discursos mediáticos, uma vez que, nestes casos, se trata de usos personalizados, idênticos ao da correspondência epistolar ou por telefone. Por seu lado, os membros dos corpos institucionais podem ocasionalmente adotar a estratégia do discurso mediático, como no caso de deputados, que utilizam a tribuna do parlamento ou o comício eleitoral ou no caso de sacerdotes que utilizam os media para se dirigirem ao público indiferenciado dos cidadãos.

Há ainda outra característica da relação enunciativa própria ao discurso mediático, a do lugar de fala a partir do qual o discurso é produzido. Esta característica tem a ver com o facto de o discurso mediático neutralizar as 
marcas enunciativas, evitando o uso das formas indexicais, dos dispositivos da linguagem que explicitam a relação dos enunciados com a pessoa, o lugar e o tempo da própria enunciação. Esta característica tem a ver com o predomínio da função referencial e com a estratégia universalizante do próprio discurso mediático.

Encontramos obviamente utilizações das marcas enunciativas no discurso mediático, mas estes casos ocorrem sobretudo nas duas ocasiões em que a lógica do discurso mediático falha ou é interrompida. Uma delas dá-se por ocasião da transição entre locutores, como nos casos em que um locutor explicita as marcas da enunciação para dar a palavra a um repórter ou a uma testemunha de acontecimentos distantes. A outra ocasião dá-se quando ocorrem ruturas no fluxo habitual do discurso, por ocasião de falhas técnicas ou pessoais que obrigam o locutor a pôr-se ele próprio em cena com a intenção de, em nome próprio ou em nome da instituição mediática que ele representa, explicar e pedir desculpa por essas ocorrências.

No discurso mediático, é particularmente visível a distinção entre diversos enunciadores, fenómenos associados a um dos aspetos da prática discursiva, a que Oswald Ducrot dá o nome de polifonia ou de pluralidade de vozes. Um locutor singular enuncia um discurso que, embora seja seu, é também de outros enunciadores.

A polifonia no discurso mediático pode situar-se a diferentes níveis, desde o mais superficial, do discurso relatado, até aos níveis mais profundos das alusões e da heterogeneidade de sentidos. No discurso relatado, o locutor cita, em estilo direto ou indireto, o discurso de outro locutor, assumindo-o como seu ou demarcando-se dele. Mais subtis são os fenómenos de polifonia que atravessam os próprios enunciados do locutor, como nos casos dos enunciados irónicos ou atravessados por múltiplos sentidos pertencentes a lugares de fala diferenciados, pondo assim em cena diferentes enunciadores.

A título de exemplo, observe-se a multiplicidade de enunciadores que o locutor traz à colação nos seguintes títulos da imprensa:

"Unidos na bagunça"

"Paz ou Pauleira. Israelenses decidem nas urnas entre o naufrágio e a continuação do diálogo com palestinos"

"Deserto irrigado. Kadafi faz implante de cabelos com médico brasileiro, a exemplo de outros carecas famosos"

\footnotetext{
${ }^{3}$ Analisei estes casos no meu livro Comunicação e Cultura. Lisboa, ed. Presença: 1994,
} pp. 167 e ss. 
"Depois dizem que Baiano é preguiçoso"

"Então fica combinado: a gente decora sua janela e você decora nosso nome"

"A fumaça da riqueza. Da planta de fumo ao cigarro na padaria, o tabagismo no Brasil é um negócio de 7 bilhões de reais"

"No corredor da Morte. Vítima da tragédia da hemodiálise de Caruaru conta como era a vida e a agonia entre amigos mortos, médicos pouco atenciosos e autoridades ausentes"

"Major foge da vaca louca"

"Procura-se um miserável. Os programas sociais têm critérios tão restritivos que ficou difícil até ser considerado pobre no país"

"Mágicos do sucesso"

"O trabalhador vai ao divã. Pressionados pelo desempenho, os metalúrgicos vivem uma crise de identidade e mudam suas posições"

"Igualdade desigual. Chega ao Brasil o debate sobre a "discriminação positiva" para proteger mulheres e negros"

"A dose é pequena para curar. Os especialistas dizem que as novas medidas para facilitar o crédito nem arranhões a economia".

"Os bombons da discórdia. A Philip Morris compra a Lacta da família Adhemar de Barros que estava brigando na Justiça"

"O último tango de Cavallo. Com a economia argentina paralisada, o presidente Menem demite seu superministro"

"Prefeitos-sabonete. A televisão faz das eleições municipais uma guerra de cifrões"

\section{A mutualidade das evidências}

Um dos problemas pragmáticos do discurso mediático tem a ver com a avaliação do grau de probabilidades de entendimento dos seus enunciados por parte do público. Como podem os seus enunciados ser entendidos por uma diversidade incomensurável de indivíduos, a partir de quadros da experiência que escapam à perceção do locutor?

Em geral, existem três tipos de evidências a partir das quais os interlocutores inferem o sentido dos discursos que trocam entre si: a presença física, a co-presença linguística e a pertença a uma comunidade da experiência do mundo. No discurso mediático, o locutor não perceciona a presença física do público e a perceção da presença física do locutor por parte do público é mediada por dispositivos que asseguram o suporte do discurso. A co-presença linguística e a comunidade da experiência do mundo desempenham, 
por isso, no caso do discurso mediático, um papel determinante no entendimento do sentido, na constituição das evidências mutuamente partilhadas, a partir das quais o público infere aquilo que o locutor quer dizer.

Para obviar às dificuldades de intercompreensão decorrentes da diversidade e da ausência dos interlocutores, o discurso mediático utiliza sobretudo os recursos da intertextualidade. É o caso do uso de elementos anafóricos, de unidades discursivas que remetem para outras, criando assim efeitos co-textuais que ancoram o discurso a um sentido intertextual, identificável pelo público, independentemente do horizonte da sua experiência individual. Deste modo, o sentido do discurso mediático converte-se num sentido autorreflexivo, em relação ao qual são situados os factos, as referências ao mundo narrado. Este fenómeno pode ser facilmente apreciado, comparando a familiaridade do público habitual de um jornal em relação ao seu discurso com a estranheza de um leitor ocasional. 